Article

\title{
A Novel Exopolysaccharide with Metal Adsorption Capacity Produced by a Marine Bacterium Alteromonas sp. JL2810
}

\author{
Zilian Zhang *, Ruanhong Cai, Wenhui Zhang, Yingnan Fu and Nianzhi Jiao * \\ State Key Laboratory of Marine Environmental Science, Institute of Marine Microbes and Ecospheres, \\ Xiamen University, Xiamen 361102, China; crh1987@163.com (R.C.); qiaobamm@163.com (W.Z.); \\ fuyingnan@xmu.edu.cn (Y.F.) \\ * Correspondence: zhangzilian@xmu.edu.cn (Z.Z.); jiao@xmu.edu.cn (N.J.); \\ Tel.: +86-592-218-4491 (Z.Z.); +86-592-288-0199 (N.J.)
}

Received: 29 March 2017; Accepted: 9 June 2017; Published: 12 June 2017

\begin{abstract}
Most marine bacteria can produce exopolysaccharides (EPS). However, very few structures of EPS produced by marine bacteria have been determined. The characterization of EPS structure is important for the elucidation of their biological functions and ecological roles. In this study, the structure of EPS produced by a marine bacterium, Alteromonas sp. JL2810, was characterized, and the biosorption of the EPS for heavy metals $\mathrm{Cu}^{2+}, \mathrm{Ni}^{2+}$, and $\mathrm{Cr}^{6+}$ was also investigated. Nuclear magnetic resonance (NMR) analysis indicated that the JL2810 EPS have a novel structure consisting of the repeating unit of [-3)- $\alpha$-Rhap-(1 $\rightarrow 3)-\alpha-\operatorname{Man} p-(1 \rightarrow 4)-\alpha-3 \mathrm{OAc}-\mathrm{GalA} p-(1 \rightarrow]$. The biosorption of the EPS for heavy metals was affected by a medium $\mathrm{pH}$; the maximum biosorption capacities for $\mathrm{Cu}^{2+}$ and $\mathrm{Ni}^{2+}$ were $140.8 \pm 8.2 \mathrm{mg} / \mathrm{g}$ and $226.3 \pm 3.3 \mathrm{mg} / \mathrm{g}$ at $\mathrm{pH} 5.0$; however, for $\mathrm{Cr}^{6+}$ it was $215.2 \pm 5.1 \mathrm{mg} / \mathrm{g}$ at $\mathrm{pH}$ 5.5. Infrared spectrometry analysis demonstrated that the groups of $\mathrm{O}-\mathrm{H}$, $\mathrm{C}=\mathrm{O}$, and $\mathrm{C}-\mathrm{O}-\mathrm{C}$ were the main function groups for the adsorption of JL2810 EPS with the heavy metals. The adsorption equilibrium of JL2810 EPS for $\mathrm{Ni}^{2+}$ was further analyzed, and the equilibrium data could be better represented by the Langmuir isotherm model. The novel EPS could be potentially used in industrial applications as a novel bio-resource for the removal of heavy metals.
\end{abstract}

Keywords: exopolysaccharide; marine bacteria; Alteromonas; metal adsorption

\section{Introduction}

Exopolysaccharides (EPS) are high-molecular weight polymers consisting mainly of carbohydrates. The composition and structure of EPS vary widely; they may be homo- or hetero-polysaccharides and may contain a number of different organic and inorganic substituents such as sulfate, phosphate, acetic acid, and acetylate [1,2]. Most marine bacteria can produce EPS, which occur in two forms: capsular polysaccharides in which the polymers are covalently bound to the cell surface; and slime polysaccharides that either remain attached (loosely bound) to the cell surface or are released into the environment [3,4]. EPS produced by marine bacteria are thought to play a role in the protection against the marine environment characterized by extreme physicochemical conditions such as low or high temperature, high pressure, low nutrient concentration, high salinity, and heavy metal presence $[2,5,6]$. EPS also present a wide range of industrial applications such as in emulsification, thickening, gel formation, anticancer treatment, and metal biosorption $[4,7,8]$. For example, EPS from Zoogloea sp. possess excellent flocculating activity [9]; EPS from Halolactibacillus miurensis show high antioxidant activity [10]; over-sulfated EPS produced by Alteromonas infernus can inhibit the invasiveness of osteosarcoma cells [11]; and EPS from strain HYD657, A. macleodii subsp. fijiensis biovar deepsane, have been developed for cosmetic applications (patent PCT 94907582-4) [12,13]. 
However, until now very few EPS structures produced by marine bacteria have been determined [2], and the characterization of EPS structures is important for the elucidation of their biological functions and ecological roles.

Many microbial EPS show biosorption activity for metal ions. Currently, pollution from heavy metals has aroused intense concern due to the large amount released into the environment and the high risks to both the environment and human health $[14,15]$. For example, high levels of $\mathrm{Ni}^{2+}$ discharged from nickel smelting, acid mine drainage, and the electroplating industries affect the lungs and kidneys and generate several gastrointestinal and skin problems in human health [16]. Chromium $\left(\mathrm{Cr}^{6+}\right)$ released from industries such as dyeing, leather tanning, and electroplating poses serious health risks from skin irritation to lung carcinoma [17]. As an important engineering material with wide industrial applications, excessive copper $\left(\mathrm{Cu}^{2+}\right)$ in the marine system has been found to damage marine life. In humans, copper toxicity leads to a neurotoxic condition known commonly as "Wilson's disease," which occurs as a result of the deposition of copper in the lenticular nucleus of the brain [18]. Thus, the efficient removal of $\mathrm{Ni}^{2+}, \mathrm{Cr}^{6+}$, and $\mathrm{Cu}^{2+}$ from industrial wastewater is essential. Several methods have been developed to remove heavy metal ions from aqueous solutions such as ion-exchange, reverse osmosis, filtration, precipitation, coagulation, and biosorption [19]. Among these methods, biosorption is regarded as one of the most promising technologies due to its advantages of low cost, short operation time, and the reusability of biomaterials [20]. The adsorption of various heavy metals by EPS produced by bacteria such as Bacillus firmus [21], Arthrobacter ps-5 [22], cyanobacteria of Synechocystis sp. BAS0671 [23], Anabaena spiroides [24], and Lyngbya putealis [25] have been reported. Although many known EPS have shown adsorption for heavy metals, further investigation for new microbial EPS is promising. There is growing interest in isolating bacterial EPS with novel functions from the ocean; however, only a small number of these bacteria can be grown in culture and most of the marine bacterial world remains unexplored [26].

Alteromonas is a common marine heterotrophic $\gamma$-proteobacterium widely distributed in the ocean [27]. The production of EPS by several strains of Alteromonas has been characterized, and most strains were isolated from deep-sea hydrothermal vents [12,28-31]. We have previously isolated EPS-producing bacteria from surface seawater collected from the South China Sea. Among the isolates, bacterium Alteromonas sp. JL2810 produced the highest level of EPS [32], and the molecular weight and composition of JL2810 EPS were characterized [32]. In this study, the structure of JL2810 EPS was determined and the biosorption of the EPS for heavy metals of $\mathrm{Cu}^{2+}, \mathrm{Ni}^{2+}$, and $\mathrm{Cr}^{6+}$ was investigated.

\section{Results and Discussion}

\subsection{Structure Analysis of JL2810 EPS}

The EPS produced by JL2810 had a high molecular weight $\left(>1.67 \times 10^{5}\right)$ and contained large amounts of galacturonic acid (GalA) [32]. In this study, the structure of the purified EPS was determined by nuclear magnetic resonance (NMR) analysis. As substitution with $O$-acetyl groups increases the complexity of NMR spectra, removal of the acetyl groups is desirable. In this study, the removal of the $\mathrm{O}$-acetyl groups was undertaken by treatment with $12.5 \%$ ammonium hydroxide solution overnight at room temperature. Comparison of the 2D NMR spectrum before and after the O-deacetylation allowed for the assignment of the $O$-acetyl location in the native material. Spectra were acquired at $70{ }^{\circ} \mathrm{C}$, which provided better resolution and lowered the viscosity of the sample.

The gHSQC spectrum showed three anomeric signals (A-H1, B-H1, C-H1) in the anomeric region $\left(\delta_{\mathrm{H}} 4.4-5.5 \mathrm{ppm}, \delta_{\mathrm{C}} 90-120 \mathrm{ppm}\right)$ (Figure 1). Most signals were assigned after the interpretation of the gCOSY, TOCSY, ROESY, and gHMBC spectra (Figures S1-S4). 
(a)

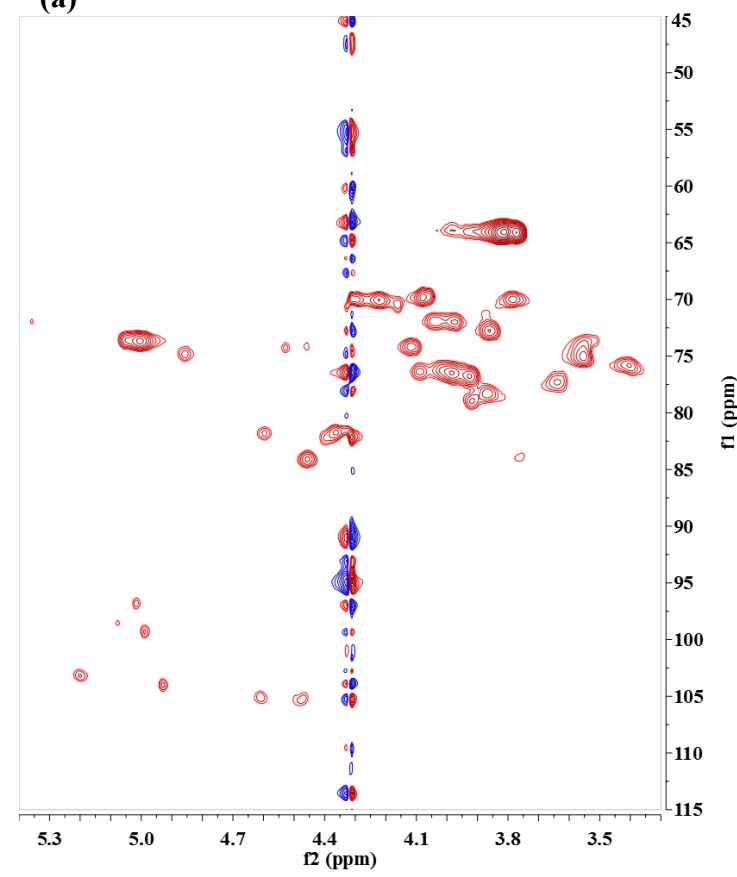

(b)

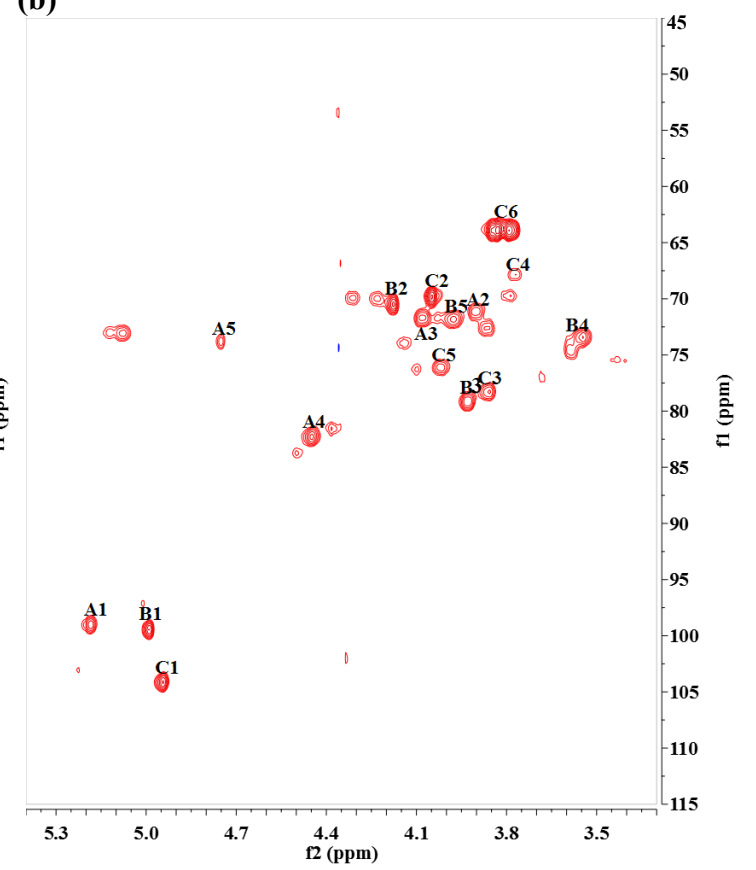

Figure 1. 2D gHSQC spectrum of JL2810 EPS. (a) Native exopolysaccharides (EPS); and (b) O-deacetylated EPS.

Homonuclear COSY and TOCSY spectra were applied for the identification of individual monosaccharide residues. The gCOSY spectrum enabled the unambiguous assignment of all $\mathrm{H} 2$ protons from the $\mathrm{H} 1 / \mathrm{H} 2$ cross-peaks (Figure S1). In the TOCSY experiment, each anomeric proton signal exhibited connectivity to all other signals for protons in the same ring (Figure S2). The intensity of connectivity depends on the magnitude of all the homonuclear coupling constants. For residue A, the weak $\mathrm{H} 1 / \mathrm{H} 4$ cross-peak $\left(\delta_{\mathrm{H} 1 / \mathrm{H} 4} 5.18 / 4.44 \mathrm{ppm}\right)$ was observed due to the small coupling constant. The magnetization transferred from the anomeric proton was inefficient due to the equatorial $\mathrm{H} 4$; therefore, long-range connectivity between $\mathrm{H} 1$ and $\mathrm{H} 2$ through $\mathrm{H} 4$ was observed, which supported the assignment of GalA. In the same manner, residues B and C were assigned as rhamnose (Rha) and mannose (Man). Based on the chemical shifts of the anomeric signals, the three residues were assigned as $\alpha$-GalAp, $\alpha$-Rhap, and $\alpha$-Manp.

The ROESY (Figure S3) and gHMBC (Figure S4) spectra provided information regarding the glycosidic linkage. The correlation signals at 5.18/3.93 (A-H1/B-H3), 4.99/3.87 (B-H1/C-H3), and 4.95/4.44 (C-H1/A-H4) in the ROESY spectrum revealed the presence of a $[-3)-\alpha$-Rhap- $(1 \rightarrow 3)-\alpha$-Manp-( $1 \rightarrow 4)-\alpha$-GalAp- $(1 \rightarrow]$ repeating unit. The appearance of cross-peaks in the gHMBC spectrum also confirmed the glycosidic linkage results.

Comparison of the NMR spectra before and after O-deacetylation showed that chemical shifts for $\mathrm{H}^{1}$ in the 4- $\alpha$-GalAp residue were upfield and other protons in the ring were downfield, indicating that the $O$-acetyl group was attached at the $4-\alpha$-GalAp residue. Signals of $\mathrm{H}^{3}$ with higher $\Delta \delta$ values when compared to other protons were observed, indicating that the $O$-acetyl group occurred at the 3-position. Chemical shifts are shown in Table 1. 
Table 1. Chemical shift of signals in ${ }^{1} \mathrm{H}$ and ${ }^{13} \mathrm{C}$ NMR spectra of JL2810 EPS.

\begin{tabular}{|c|c|c|c|c|c|c|c|c|c|c|}
\hline \multirow{2}{*}{ EPS } & \multirow{2}{*}{ Compoumd } & \multirow{2}{*}{ Residue } & \multirow{2}{*}{ Nuclear } & \multicolumn{6}{|c|}{ Chemical Shift (ppm) } & \multirow{2}{*}{$\begin{array}{c}\text { NOE } \\
\text { HMBC }\end{array}$} \\
\hline & & & & 1 & 2 & 3 & 4 & 5 & 6 & \\
\hline \multirow{6}{*}{ Deacetylted } & \multirow[b]{2}{*}{$\mathbf{A}$} & \multirow{2}{*}{ 4- $\alpha$-GalAp } & ${ }^{1} \mathbf{H}$ & 5.18 & 3.9 & 4.08 & 4.44 & 4.75 & - & B-H3 \\
\hline & & & ${ }^{13} \mathrm{C}$ & 99 & 71 & 71.3 & 82.4 & 73.7 & 176.2 & - \\
\hline & \multirow{2}{*}{ B } & \multirow{2}{*}{ 3- $\alpha$-Rhap } & ${ }^{1} \mathrm{H}$ & 4.99 & 4.19 & 3.93 & 3.56 & 3.98 & 1.27 & $\mathrm{C}-\mathrm{H} 3$ \\
\hline & & & ${ }^{13} \mathrm{C}$ & 99.3 & 70.4 & 79 & 73.4 & 71.7 & 19.6 & $\mathrm{C}-\mathrm{C} 3$ \\
\hline & \multirow{2}{*}{$\mathrm{C}$} & \multirow{2}{*}{ 3- $\alpha$-Manp } & ${ }^{1} \mathbf{H}$ & 4.95 & 4.05 & 3.87 & 3.77 & 4.02 & $3.83 / 3.79$ & A-H4 \\
\hline & & & ${ }^{13} \mathrm{C}$ & 104 & 69.8 & 78.2 & 67.7 & 75.9 & 63.8 & $\mathrm{~A}-\mathrm{C} 4$ \\
\hline \multirow{2}{*}{ Native EPS } & \multirow{2}{*}{$\mathbf{A}^{\prime}$} & 3-OAc- & ${ }^{1} \mathbf{H}$ & 5.09 & 3.98 & 5.07 & 4.61 & 4.88 & - & \\
\hline & & 4- $\alpha$-GalAp & ${ }^{13} \mathrm{C}$ & 98.5 & 71.9 & 73.5 & 81.7 & 74.7 & 176.2 & \\
\hline
\end{tabular}

Carbon chemical shifts in italics; glycosylated, downfield carbon resonances in bold.

The polysaccharide was found to consist of a repeating unit of [-3)- $\alpha$-Rhap-(1 $1 \rightarrow 3)-\alpha-$ Manp-(1 $\rightarrow 4)$ - $\alpha$-3OAc-GalAp- $(1 \rightarrow]$ (Figure 2$)$.

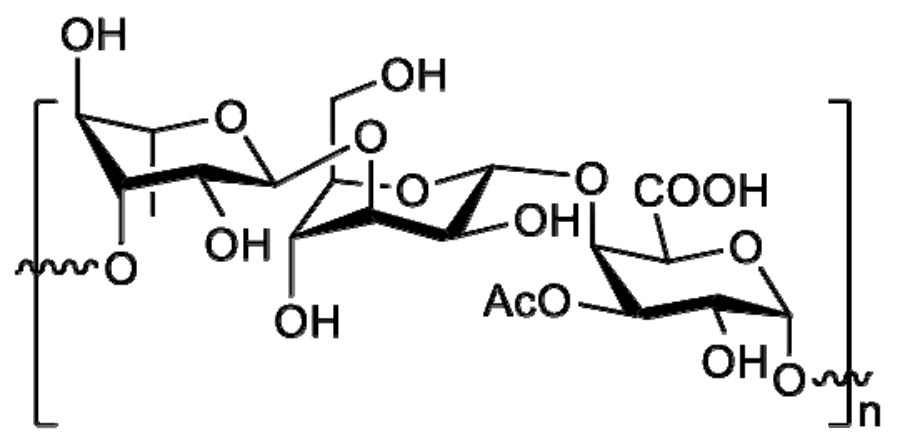

Figure 2. Chemical structure of the repeating unit of JL2810 EPS.

Currently, only limited structural data for EPS produced by strains of Alteromonas are available, and nearly all of the strains were isolated from a deep-sea hydrothermal vent $[13,28,33,34]$. The EPS produced by the Alteromonas strains showed diverse composition and structure. For example, the EPS produced by strain ST716, A. macleodii subsp. fijiensis, were found to have a branched hexasaccharide repeating unit containing Glc, Gal, Man, GlcA, and GalA [34]. The repeating unit of EPS produced by the strain GY785 (belonging to the mesophilic species $A$. infernus) was a nonasaccharide with four types of monosaccharides: Glc, Gal, GalA, and GlcA [33]. In this study, we first determined the structure of the EPS produced by the Alteromonas strain JL2810 isolated from a normal marine environment. The structure of the EPS produced by JL2810 differed from that of EPS produced by other marine bacteria [35] and Alteromonas strains isolated from the deep-sea hydrothermal vent [13,28,33,34]. The repeating unit of EPS from JL2810 was a trisaccharide without branching and contained three types of monosaccharides (GalA, Man, and Rha). Residues of Gal and GlcA were identified in the EPS produced by deep-sea Alteromonas strains, but not in the EPS of JL2810. In contrast, the Rha residue was specifically identified in the EPS produced by JL2810. Only $\alpha$-linkages were present in the EPS of JL2810; however, both $\alpha$-and $\beta$-linkages were found in the EPS from deep-sea Alteromonas strains $[13,28,33,34]$. The EPS produced by JL2810 also differed from that produced by the moderately halophilic strain A. hispanica $\mathrm{F}_{2} 3^{\mathrm{T}}$ isolated from inland hypersaline habitats in Spain. The EPS form A. hispanica $\mathrm{F} 23^{\mathrm{T}}$ contained four types of monosaccharides (Glc, Man, Rha, and xylose) without uronic acid, and its structure has yet to be determined [36]. These results indicate that the EPS produced by JL2810 have a novel structure that differs from known EPS produced by other Alteromonas strains.

As far as the microbial biodiversity is concerned, bacterial EPS exhibit a wide range of chemical structures [2]. Even closely related bacteria from different subspecies of $A$. macleodii produced very different EPS under the same growth conditions [12]. Based on the phylogenetic analysis results, 
the strain JL2810 was most closely related to A. marina SW-47 ${ }^{\mathrm{T}}$ [37]. Thus, the novel EPS produced by JL2810 may represent the characteristics of EPS produced by a species of $A$. marina. However, no EPS produced by $A$. marina has been reported and whether JL2810 belongs to the species of A. marina requires further analysis. Additional EPS produced by strains of $A$. marina should be further characterized.

\subsection{Adsorption for Metal Ions}

\subsubsection{Effect of $\mathrm{pH}$}

JL2810 EPS showed the adsorption capacity for $\mathrm{Cu}^{2+}, \mathrm{Ni}^{2+}$, and $\mathrm{Cr}^{6+}$ (Figure 3). The adsorption capacity for the metals was affected by $\mathrm{pH}$. For $\mathrm{Cu}^{2+}$ and $\mathrm{Ni}^{2+}$, the maximum adsorptions were $140.8 \pm 8.2 \mathrm{mg} / \mathrm{g}$ and $226.3 \pm 3.3 \mathrm{mg} / \mathrm{g}$ at $\mathrm{pH} 5.0$, but for $\mathrm{Cr}^{6+}$, this value was $215.2 \pm 5.1 \mathrm{mg} / \mathrm{g}$ at $\mathrm{pH}$ 5.5. Similar trends were also observed by Ye [22] and Zhou [38]. The medium $\mathrm{pH}$ affects the solubility of metals and the ionization state of the functional groups of EPS. At low $\mathrm{pH}$, the adsorption of heavy metals was possibly inhibited due to the competition between hydrogen and metals on the sorption sites. With an increase in $\mathrm{pH}$, the negative charge density on the EPS surface may increase due to the deprotonation of the metal binding sites, and thus increase metal adsorption [39], which corresponded to the maximum adsorption capacity obtained at $\mathrm{pH} 5.0$ for $\mathrm{Ni}^{2+}$ and $\mathrm{Cu}^{2+}$, and at pH 5.5 for $\mathrm{Cr}^{6+}$, respectively (Figure 3). The medium $\mathrm{pH}$ may also affect the ionization state of the function group of the EPS. It was indicated that carboxylic and phosphoric groups played a major role in the complexation of metal at $\mathrm{pH}$ 7.0, and the ability of EPS to complex heavy metals increased with the EPS phosphoric content [14]. However, based on the composition and structure analyses, no phosphoric group was detected in JL2810 EPS, which may be related to the relatively low adsorption capacity observed at $\mathrm{pH}$ 7.0.

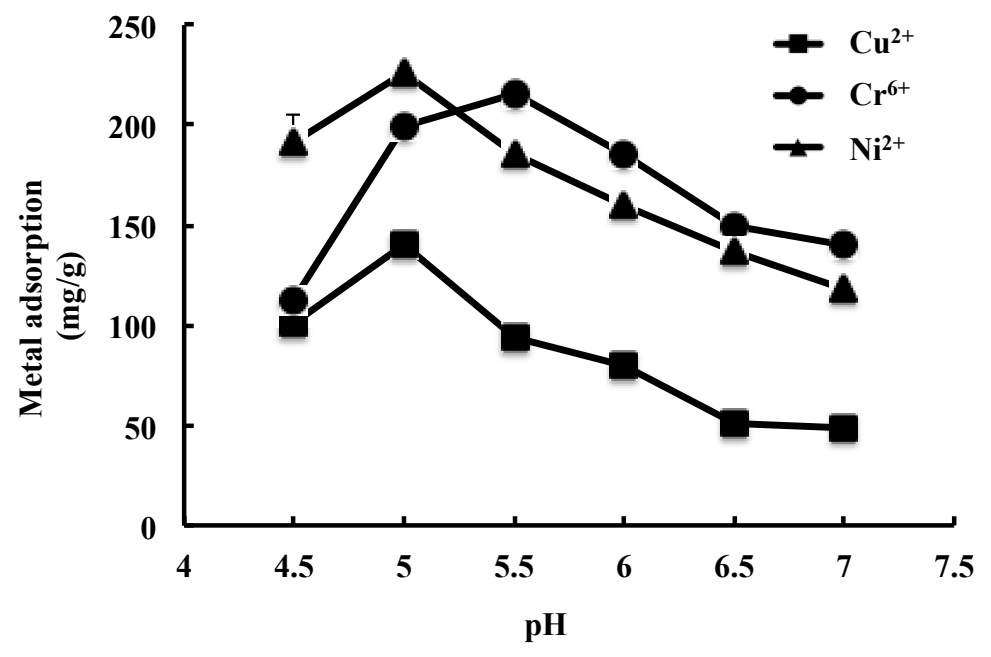

Figure 3. Effect of $\mathrm{pH}$ on the adsorption of JL2810 EPS for metals.

\subsubsection{FT-IR Analysis}

The adsorption of heavy metals by EPS is energy independent, and can be caused by interaction between metal cations and functional groups of EPS. In this study, the functional group of JL2810 EPS for adsorption with the three heavy metals was analyzed by fourier transform infrared spectroscopy (FT-IR). As shown in the Figure 4, there were several distinct and characteristic sharp stretching frequencies of chemical groups contained in JL2810 EPS. The peak assignments of the EPS were as follows: $3400-3200 \mathrm{~cm}^{-1}$ was related to the stretch vibration of the O-H or hydrogen bond existing in all polymers; the signals at $3000-2800 \mathrm{~cm}^{-1}$ were related to the stretch vibration of the $\mathrm{C}-\mathrm{H}$ bond; the signals at $1850-1600 \mathrm{~cm}^{-1}$ were due to the stretch vibration of the $\mathrm{C}=\mathrm{O}$ bond; the signals at 
$1400-1370 \mathrm{~cm}^{-1}$ were attributed to the vibration of the C-O bond; the signals at $1240 \mathrm{~cm}^{-1}$ were due to the deformation vibration of the $\mathrm{C}=\mathrm{O}$ bond; and the signals at $900-1150 \mathrm{~cm}^{-1}$ were for the $\mathrm{C}-\mathrm{O}-\mathrm{C}$ bond [14].

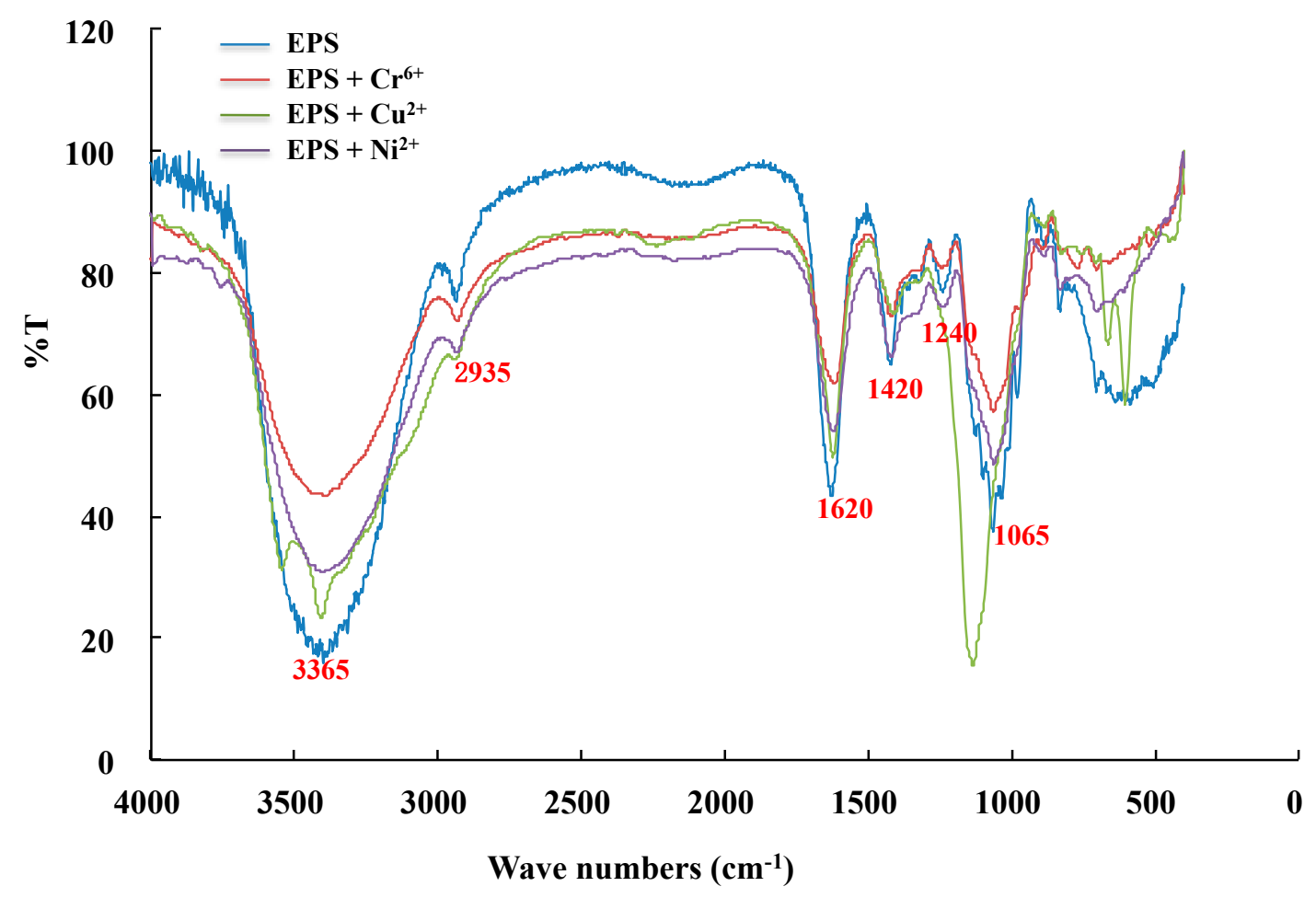

Figure 4. FT-IR spectra of JL2810 EPS before and after loading of $\mathrm{Cu}^{2+}, \mathrm{Ni}^{2+}$, and $\mathrm{Cr}^{6+}$.

In comparing JL2810 EPS and metal-laden EPS, it was observed that there were shifts in wave numbers of dominant peaks at $3365 \mathrm{~cm}^{-1}, 1620 \mathrm{~cm}^{-1}$, and $1065 \mathrm{~cm}^{-1}$, which represented the function groups of $\mathrm{O}-\mathrm{H}, \mathrm{C}=\mathrm{O}$, and $\mathrm{C}-\mathrm{O}-\mathrm{C}$, respectively (Figure 4). These shifts in wave number corresponded to the metal binding process taking place on the surface of the adsorption. This is because the $\mathrm{O}$ of the polysaccharide structure complexes with metal in adsorption process to reduce the electron cloud density of functional groups containing oxygen and to change their vibration frequency and vibration intensity [14]. Based on the FT-IR analysis results, the groups of $\mathrm{O}-\mathrm{H}, \mathrm{C}=\mathrm{O}$, and C-O-C in JL2810 EPS played an important role in the adsorption for the heavy metals.

We noticed that among the three metal-laden EPS samples, significant shifts were observed after the loading of $\mathrm{Cu}^{2+}$ (Figure 4). It was indicated that the $\mathrm{Cu}^{2+}$ easily bound the carboxyl groups of EPS [15]. These results suggested that the biosorption of EPS with heavy metals is selective, which depends on the structure and functional groups of the adsorbent as well as the state, size, and bond energy of metal ions [22].

The adsorption of heavy metals by EPS can be caused by the interaction between metals and the negative charge of the acidic function groups of EPS [38]. It was indicated that JL2810 EPS contained a large amount of GalA (42\%) [32]. Similarly, it was indicated that the EPS produced by Alteromonas isolated from deep-sea hydrothermal vents also contained relatively large amount of acidic sugars such as GlcA and GalA [13,28,33,34]. The EPS that showed high metal adsorption capacity usually contained relatively large amounts of uronic acid. For example, the EPS from Bacillus firmus contained $38 \%$ uronic acid, and showed very high metal adsorption capacities $(722-1103 \mathrm{mg} / \mathrm{g})$ for $\mathrm{Pb}^{2+}, \mathrm{Cu}^{2+}$, and $\mathrm{Zn}^{2+}$ [21]. For cyanobacterium Synechocystis sp. BASO671, EPS production was increased by the metal ions of $\mathrm{Cr}^{6+}$ and $\mathrm{Cd}^{2+}$, and the composition of uronic acid in the cyanobacterial EPS was increased by $\mathrm{Cr}^{6+}$ and $\mathrm{Cd}^{2+}$ treatment [23]. In Pseudomonas syringae, $\mathrm{Cu}^{2+}$ induced the production of 
EPS (alginate) that contained high levels of uronic acid [40]. In contrast, the EPS from A. hispanica F23 did not contain uronic acid, and their metal binding capacity was very low [36]. These results suggest that uronic acid GalA with the acetyl group in JL2810 EPS may play important roles in the adsorption of metals.

\subsubsection{Adsorption Isotherms}

The initial metal concentration plays an important role in the process of biosorption. As shown in Figure 5, the adsorption capacity increased from 33.5 to $275 \mathrm{mg} / \mathrm{g}$ of EPS as the initial $\mathrm{Ni}^{2+}$ concentration increased from $40 \mathrm{mg} / \mathrm{L}$ to $400 \mathrm{mg} / \mathrm{L}$. However, $\mathrm{Ni}^{2+}$ concentration above $400 \mathrm{mg} / \mathrm{L}$ did not increase adsorption significantly and remained almost constant (around $330 \mathrm{mg} / \mathrm{L}$ ), indicating saturation of all the binding sites on the sorbent surface beyond a particular concentration (Figure 5).

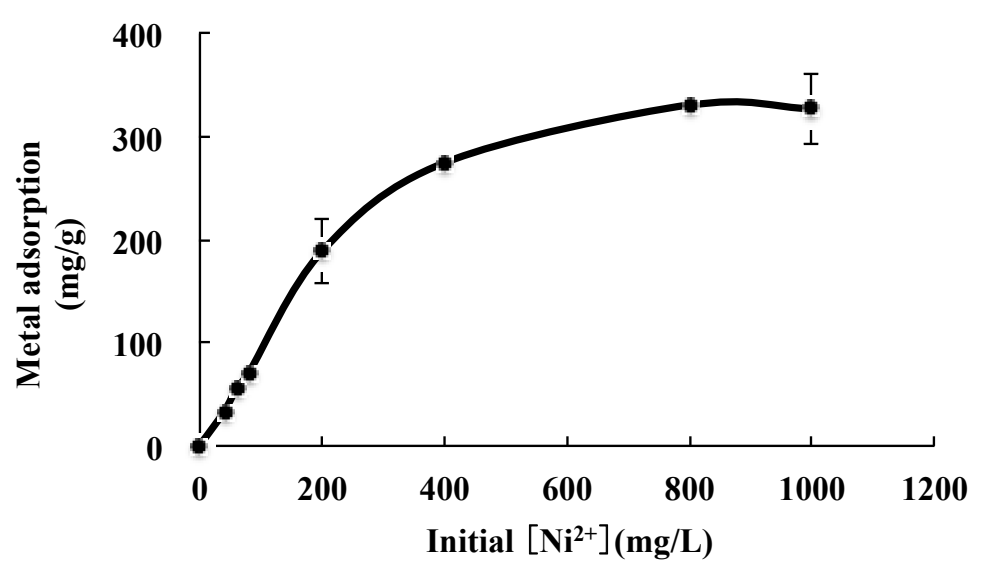

Figure 5. Effect of initial $\mathrm{Ni}^{2+}$ concentration on the adsorption with JL2810 EPS.

The distribution of metal ions between the liquid phase and biosorbent in the equilibrium adsorption process can generally be described by several isotherms based on a set of assumptions related to the heterogeneity/homogeneity of adsorbents and the type of coverage [25]. Among these models, Langmuir and Freundlich models are those most frequently employed and were thus used in this study to describe the adsorption equilibrium of $\mathrm{Ni}^{2+}$ on JL2810 EPS. The Langmuir model is based on the assumption of monolayer adsorption onto a solid surface with a definite number of identical sites, while the Freundlich equation is based on the biosorption of an heterogeneous surface [24,25]. The linearized Langmuir and Freundlich adsorption isotherms along with the corresponding parameters evaluated from the isotherms are shown in Figure 6a,b, respectively. The adsorption capacity calculated from Langmuir equation $\left(Q_{0}=344.83 \mathrm{mg} / \mathrm{g}\right)$ is higher than that from Freundlich equation $\left(K_{f}=32.29 \mathrm{mg} / \mathrm{g}\right)$, and closest to the maximum adsorption data observed ( $330 \mathrm{mg} / \mathrm{g}$ ) (Figure 5). This fact indicated that the Langmuir isotherm model with a higher correlation coefficient $\left(R^{2}=0.9866\right)$ could better represent the equilibrium data than the Freundlich isotherm model $\left(R^{2}=0.6978\right)$. Similar results were reported by other studies, indicating that the biosorption of $\mathrm{Cr}^{6+}$ and $\mathrm{Cu}^{2+}$ to bacterial EPS could be better fitted by the Langmuir model than the Freundlich model $[25,38]$. Whether the Langmuir isotherm model is also suitable for describing the adsorption of the $\mathrm{Cr}^{6+}$ and $\mathrm{Cu}^{2+}$ on JL2810 EPS needs to be further studied. For the metal $\mathrm{Ni}^{2+}$, a dimensionless constant called separation factor $\left(R_{L}\right)$ was also calculated to test the favorability of adsorption, and the values of $R_{L}$ for the present biosorbent were in the range of $0.2-0.9$, confirming the favorable adsorption of $\mathrm{Ni}^{2+}$ by JL2810 EPS. 
(a)

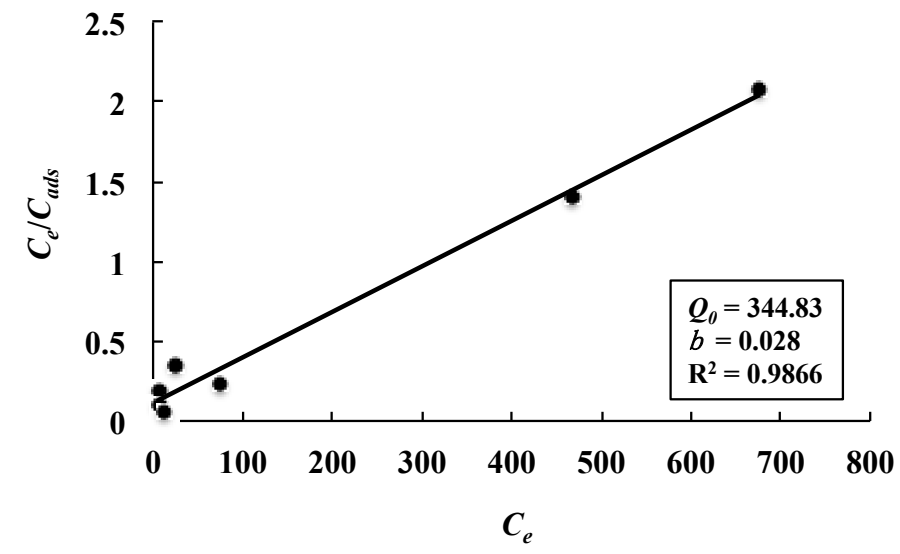

(b)

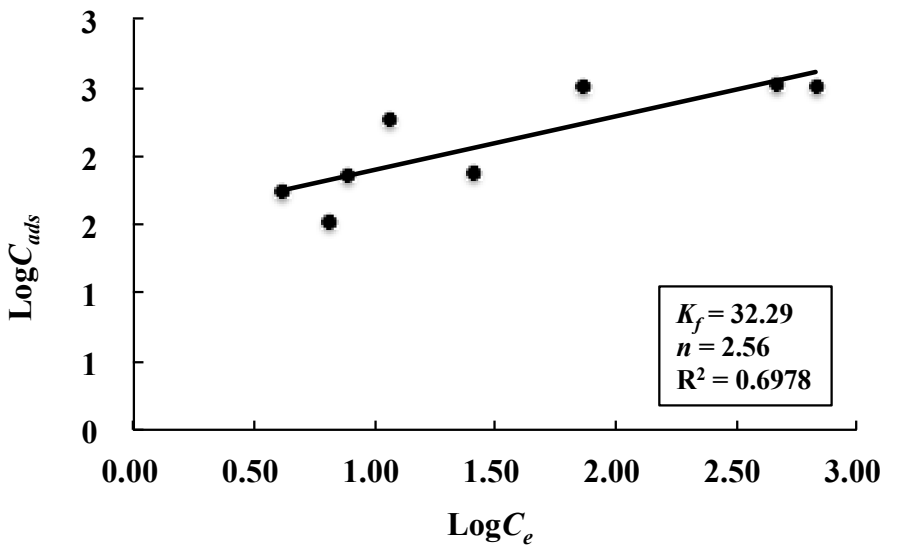

Figure 6. Linearized Langmuir and Freundlich adsorption isotherms for $\mathrm{Ni}^{2+}$ by the EPS: (a) Langmuir isotherm; and (b) Freundlich isotherm. The $C_{a d s}$ is the amount of metal adsorbed per unit of dry weight $(\mathrm{mg} / \mathrm{g}) ; C_{e}$ is the metal concentration remaining in solution at equilibrium $(\mathrm{mg} / \mathrm{L})$.

In the Langmuir model, the value of $Q_{0}$ represents the maximum adsorption capacity and the value of $b$ is related to the affinity of the binding sites. We noticed that both the values of $Q_{0}$ and $b$ were comparable with that of gelation for $\mathrm{Pb}^{2+}, \mathrm{Cu}^{2+}$, and $\mathrm{Cd}^{2+}$ with alginate $\left(Q_{0}: 167-435 \mathrm{mg} / \mathrm{g}\right.$; $b: 0.011-0.046 \mathrm{~L} / \mathrm{mg}$ ), a highly promising material for the removal of heavy metals from wastewater [41]. The adsorption capacities of JL2810 EPS for $\mathrm{Cu}^{2+}, \mathrm{Ni}^{2+}$, and $\mathrm{Cr}^{6+}$ were also comparable to that of EPS produced by bacterial strains originating from deep-sea hydrothermal vents $(77-316 \mathrm{mg} / \mathrm{g}$ for zinc, cadmium and lead) [42], but 3-5 times higher than that of EPS (40-48 $\mathrm{mg} / \mathrm{g}$ for $\mathrm{Cd}^{2+}$ and $\left.\mathrm{Cu}^{2+}\right)$ produced by the marine bacterium Wanggia profunda SM-87 [38]. The high metal adsorption capacity of JL2810 EPS suggested that the EPS have a potential use in industrial applications as a novel bio-resource for the removal of heavy metals from polluted environments.

Furthermore, it was indicated that at the $\mathrm{pH}$ of ambient seawater, anionically charged EPS could remove more than $99 \%$ of heavy metals such as zinc and silver [43]. The binding of dissolved ions by EPS is considered essential in the vertical transport of metal ions in the ocean [44]. Since Alteromonas is widely distributed in the ocean [27] and can produce large amounts of EPS [32], the acidic EPS produced by Alteromonas may be important for the metal cycle in the ocean.

\section{Materials and Methods}

\subsection{Bacterial Cultivation}

Alteromonas sp. JL2810 isolated from the surface seawater of the South China Sea [32] was used for EPS isolation. A basal medium (BM) with glucose (Glc) as a sole carbon source was used to culture JL2810 and EPS production. The BM contained $1.9 \% \mathrm{NaCl}, 0.03 \% \mathrm{NH}_{4} \mathrm{Cl}, 0.03 \% \mathrm{KCl}$, 
$0.04 \% \mathrm{~K}_{2} \mathrm{HPO}_{4}, 0.05 \% \mathrm{MgSO}_{4} \cdot 7 \mathrm{H}_{2} \mathrm{O}, 0.003 \% \mathrm{CaCl}_{2} \cdot 7 \mathrm{H}_{2} \mathrm{O}$, and $1 \% \mathrm{Glc}$, $\mathrm{pH}$ 7.6. The cultivation was performed using a 3.7 L KLF 2000 bioreactor (Bioengineering, Wald, Switzerland), as described previously in Reference [32].

\subsection{EPS Isolation and Purification}

After cultivation, bacterial cells were removed from the culture medium by centrifugation $(8000 \times g, 20 \mathrm{~min})$ and filtered through a $0.22-\mu \mathrm{m}$ Millex-GF filter unit. Three volumes of cold ethanol $\left(-20^{\circ} \mathrm{C}\right)$ were added to one volume of supernatant and the mixture was incubated at $4{ }^{\circ} \mathrm{C}$ overnight. The precipitate was harvested by centrifugation $(12,000 \times g, 30 \mathrm{~min})$, washed with $75 \%$ ethanol three times, and then dissolved in water. Proteins were removed using the Sevag method [45]. After centrifugation, the EPS solution was dialyzed (3500 Da cutoff) against water for $24 \mathrm{~h}$. Next, the EPS were re-precipitated with three volumes of ethanol at $4{ }^{\circ} \mathrm{C}$ overnight and then harvested by centrifugation as mentioned above. The EPS were freeze-dried and used as crude EPS.

The crude EPS were dissolved in water at a concentration of $5 \mathrm{~g} / \mathrm{L}$ and purified using anion-exchange chromatography with a DEAE-Sepharose Fast Flow column $(1.6 \times 30 \mathrm{~cm})$ (GE Healthcare, Little Chalfont, UK). EPS were eluted with $20 \mathrm{~mL}$ of $\mathrm{H}_{2} \mathrm{O}$ at a flow rate of $0.5 \mathrm{~mL} / \mathrm{min}$ followed by a $\mathrm{NaCl}$ gradient $(30 \mathrm{~mL})$ ranging $0-2 \mathrm{M}$ at a flow rate of $1 \mathrm{~mL} / \mathrm{min}$. The process was carried out on an AKTA purifier FPLC system (Amersham Biosciences, Amersham, UK). Each elution fraction ( $2 \mathrm{~mL}$ ) was collected, and the EPS content was assayed using the phenol/sulfuric acid method. Major EPS-containing fractions were combined. After dialysis against distilled water, the EPS were freeze-dried and used as purified EPS.

\subsection{EPS Structure Analysis}

The glycosyl-linkages of the purified EPS were analyzed. Both native and O-deacetylated EPS were analyzed by nuclear magnetic resonance (NMR). The native sample was deuterium-exchanged twice by lyophilization in $\mathrm{D}_{2} \mathrm{O}\left(99.9 \% \mathrm{D}\right.$, Aldrich, St. Louis, MO, USA), and dissolved in $0.5 \mathrm{~mL} \mathrm{D}_{2} \mathrm{O}$ (99.96\% D, Cambridge Isotope, Tewksbury, MA, USA). Next, $10 \mu \mathrm{L}$ of $20 \%$ acetone in $\mathrm{D}_{2} \mathrm{O}$ was added and placed into a 5-mm NMR tube. An O-deacetylated sample was also prepared for NMR analysis to elucidate the structure. The sample was adjusted to $\mathrm{pH} 11.0$ by adding $12.5 \%$ ammonium hydroxide solution and stored overnight at room temperature. Next, dialysis (2000 Da cutoff) was applied to remove the salt. The sample was deuterium-exchanged as described above.

NMR spectra were acquired at $600\left({ }^{1} \mathrm{H}\right)$ or $150 \mathrm{MHz}\left({ }^{13} \mathrm{C}\right)$ on a Biofuel-600 instrument at $70{ }^{\circ} \mathrm{C}$ (Agilent Technologies, Santa Clara, CA, USA). One-dimensional (1D) proton and two-dimensional (2D) gradient correlation spectroscopy (gCOSY), total correlation spectroscopy (TOCSY), rotating-frame overhauser effect spectroscopy (ROESY), gradient heteronuclear single quantum correlation spectroscopy (gHSQC), and gradient heteronuclear multiple bond correlation (gHMBC) spectra were acquired. Chemical shifts were referenced relative to a standard 4,4-dimethyl-4-silapentane-1-sulfonic acid (DSS) (0.000 ppm) by setting the chemical shifts of acetone to $2.218 \mathrm{ppm}$ in the proton dimension and $33.0 \mathrm{ppm}$ in the carbon dimension. The 1D proton spectrum was signal-averaged from 64 scans. The 2D gCOSY, TOCSY, and NOESY spectra were acquired in 32 scans per increment for 96 increments, and the gHSQC and gHMBC spectra were acquired in 256 scans and 64 increments. Spectral width was $4500 \mathrm{~Hz}$ for the proton spectrum and $11,000 \mathrm{~Hz}$ for the carbon spectrum. Acquisition time was $2.5 \mathrm{~s}$ for the $1 \mathrm{D}$ proton spectrum and $150 \mathrm{~ms}$ for the 2D spectra. The mixing time for the TOCSY experiment was $80 \mathrm{~ms}$.

\subsection{Metal Adsorption Experiments}

\subsubsection{Effect of $\mathrm{pH}$ on the Metal Adsorption}

The adsorption capacity of the EPS for heavy metals was evaluated as described by Salehizadeh and Shojaosadatiet with some modification [21]. Stock solutions of $\mathrm{Cu}^{2+}, \mathrm{Cr}^{6+}$, and $\mathrm{Ni}^{2+}(1 \mathrm{~g} / \mathrm{L})$ were 
prepared by dissolving specific quantities of $\mathrm{CuSO}_{4}, \mathrm{~K}_{2} \mathrm{Cr}_{2} \mathrm{O}_{7}$, and $\mathrm{NiCl}_{2}$ in deionized water and working standards were obtained by further dilution. The adsorption experiment was carried out by adding $1.5 \mathrm{~mL}$ EPS solution $(1 \mathrm{~g} / \mathrm{L})$ and $1.5 \mathrm{~mL}$ heavy metal solution $(1 \mathrm{~g} / \mathrm{L})$ in a $15-\mathrm{mL}$ centrifuge tube and then on a shaker at $200 \mathrm{rpm}$. After incubation for $15 \mathrm{~min}$, three volumes of chilled ethanol were added and the sample was centrifuged at $10,000 \times g$ for $10 \mathrm{~min}$. Next, residual $\mathrm{Cu}^{2+}, \mathrm{Cr}^{6+}$, and $\mathrm{Ni}^{2+}$ in the supernatant were determined using an inductively coupled plasma atomic emission spectrometer (Optima 7000 DV, Perkin Elmer, Waltham, MA, USA). To investigate the effect of $\mathrm{pH}$ on the adsorption, the $\mathrm{pH}$ of the metal solution was adjusted to $4.5-7.0$ by $\mathrm{HCl}$ or $\mathrm{NaOH}$. All experiments were carried out in triplicate, the experimental data were presented as mean values \pm standard deviations. Treatment without EPS solution was used as a control.

The amount of a metal adsorbed onto JL2810 EPS at equilibrium, $Q(\mathrm{mg} / \mathrm{g})$, was calculated using the equation $Q=\left(C_{i}-C_{e}\right) / C_{e p s}$, where $C_{i}$ and $C_{e}$ are the initial and residual concentrations of metals, respectively, and $C_{e p s}$ is the EPS concentration.

\subsubsection{Infrared Analysis}

The infrared (IR) spectrum of EPS was determined using a fourier transform infrared spectrophotometer Thermo Nicolet Avatar 370 (Thermo Nicolet, Madison, WI, USA). Samples of purified EPS and metal-laden EPS were prepared for FT-IR measurement. To prepare the metal-laden EPS, purified EPS were incubated with metals of $\mathrm{Cu}^{2+}, \mathrm{Ni}^{2+}$, and $\mathrm{Cr}^{6+}$ as described above. After incubation for $15 \mathrm{~min}$, chilled ethanol was added to the solution, and then sample was centrifuged at $10,000 \times g$ for $10 \mathrm{~min}$. The pellet was washed by $70 \%$ ethanol twice, and then freeze-dried. The freeze-dried sample was ground with $\mathrm{KBr}$ powder and pressed into pellets for FT-IR measurement in the frequency range of $4000-400 \mathrm{~cm}^{-1}$ [22].

\subsubsection{Analysis of Adsorption Isotherms}

Adsorption isotherms of JL2810 EPS with $\mathrm{Ni}^{2+}$ were analyzed. Briefly, JL2810 EPS were incubated with different $\mathrm{Ni}^{2+}$ concentrations ranging from 0 to $1000 \mathrm{mg} / \mathrm{L}$ (pH 5.0). Other processes were the same as described above. The adsorption of $\mathrm{Ni}^{2+}$ with the EPS was analyzed using two models; Langmuir and Freundlich [24,25].

For the Langmuir model, the equation can be represented as $C_{a d s}=Q_{0} b C_{e} /\left(1+b C_{e}\right) . C_{a d s}$ is the amount of metal adsorbed per unit of dry weight $(\mathrm{mg} / \mathrm{g}) ; C_{e}$ is the metal concentration remaining in solution at equilibrium $(\mathrm{mg} / \mathrm{L}) ; Q_{0}(\mathrm{mg} / \mathrm{g})$ and $b(\mathrm{~L} / \mathrm{mg})$ are the Langmuir constants that can be determined from the linear plot of $C_{e} / C_{a d s}$ versus $C_{e}$. $Q_{0}$ represents the maximum adsorption capacity when the surface is fully covered with metal ions and the constant $b$ is related to the affinity of the binding sites [25]. Furthermore, a dimensionless constant called the separation factor $\left(R_{L}\right)$ was also calculated to test the favorability of adsorption as per the equation of $R_{L}=1 /\left(1+b C_{i}\right)$, where $b$ is the Langmuir isotherm constant and $C_{i}$ is the initial metal ion concentration $(\mathrm{mg} / \mathrm{L})$. This parameter explains the isotherm as follows: $R_{L}>1$, unfavorable; $R L=1$, linear; $0<R_{L}<1$, favorable; $R_{L}=0$, irreversible [25].

For the Freundlich model, the equation can be represented as $\log C_{a d s}=\log K_{f}+\mathrm{n}^{-1}\left(\log C_{e}\right) . C_{a d s}$ and $C_{e}$ are the same as described above. $K_{f}$ is the Freundlich constant indicating adsorbent capacity $(\mathrm{mg} / \mathrm{g})$ and $n$ is Freundlich exponent known as adsorbent intensity. The constant $K_{f}$ and $n$ can be determined from the linear plot of $\log C_{a d s}$ versus $\log C_{e}$ [25].

\section{Conclusions}

In this study, the structure of JL2810 EPS was analyzed by NMR analysis. The data indicated that EPS have a novel structure consisting of a repeating unit of $[-3)-\alpha-\operatorname{Rhap}-(1 \rightarrow 3)-\alpha-$ Man $p-(1 \rightarrow 4)-\alpha-3 \mathrm{OAc}-\mathrm{GalA} p-(1 \rightarrow]$. The EPS showed high adsorption capacity for $\mathrm{Cu}^{2+}, \mathrm{Ni}^{2+}$, and $\mathrm{Cr}^{6+}$. The adsorption of the EPS for heavy metals was affected by a medium $\mathrm{pH}$. The groups of $\mathrm{O}-\mathrm{H}$, $\mathrm{C}=\mathrm{O}$, and C-O-C were the main function groups for adsorption of JL2810 EPS with the heavy metals. 
The Langmuir and Freundlich models were employed to describe the biosorption equilibrium data for $\mathrm{Ni}^{2+}$, and it was found that the equilibrium data could be better represented by the Langmuir isotherm model. The high adsorption capacity suggested that JL2810 EPS has potential in industrial applications as a novel bio-resource for the removal of heavy metals.

Supplementary Materials: The following are available online at www.mdpi.com/1660-3397/15/6/175/s1, Figure S1: 2D gCOSY spectra of native and deacetyled JL2810 EPS, Figure S2: 2D TOCSY spectra of native and deacetyled JL2810 EPS, Figure S3: 2D ROESY spectra of native and deacetyled JL2810 EPS, Figure S4: 2D gHMBC spectrum of deacetyled JL2810 EPS.

Acknowledgments: This work was supported by the National Key Research Program (2016YFA0601400), a State Oceanic Administration (SOA) project (GASI-03-01-02-05), the National Key Basic Research Program of China (2013CB955700), NSFC project (91428308), and the project CNOOC-KJ 125 FZDXM 00TJ 001-2014. This study is a contribution to the international IMBER project. This study was also supported by the Chemical Sciences, Geosciences and Biosciences Division, Office of Basic Energy Sciences, U.S. Department of Energy grant (DE-FG02-93ER20097) to Parastoo Azadi at the Complex Carbohydrate Research Center. We would like to thank Xiaodong Gao for drawing up the structure of the EPS.

Author Contributions: Z.Z. and N.J. conceived and designed the experiments; R.C., W.Z. and Y.F. performed the experiments and data analyses; and Z.Z. and R.C. wrote the paper.

Conflicts of Interest: The authors declare no conflict of interest.

\section{References}

1. Sutherland, I.W. Biotechnology of Microbial Exopolysaccharides; Cambridge University Press: New York, NY, USA, 1990.

2. Poli, A.; Anzelmo, G.; Nicolaus, B. Bacterial exopolysaccharides from extreme marine habitats: Production, characterization and biological activities. Mar. Drugs 2010, 8, 1779-1802. [CrossRef] [PubMed]

3. Heissenberger, A.; Leppard, G.G.; Herndl, G.J. Relationship between the intracellular integrity and the morphology of the capsular envelope in attached and free-living marine bacteria. Appl. Environ. Microbiol. 1996, 62, 4521-4528. [PubMed]

4. Manivasagan, P.; Kim, S.K. Extracellular polysaccharides produced by marine bacteria. Adv. Food Nutr. Res. 2014, 72, 79-94. [PubMed]

5. Sutherland, I.W. Biofilm exopolysaccharides: A strong and sticky framework. Microbiology 2001, 147 Pt 1, 3-9. [CrossRef] [PubMed]

6. Mitra, S.; Sana, B.; Mukherjee, J. Ecological roles and biotechnological applications of marine and intertidal microbial biofilms. Adv. Biochem. Eng. Biotechnol. 2014, 146, 163-205. [PubMed]

7. Freitas, F.; Alves, V.D.; Reis, M.A. Advances in bacterial exopolysaccharides: From production to biotechnological applications. Trends Biotechnol. 2011, 29, 388-398. [CrossRef] [PubMed]

8. Kumar, A.S.; Mody, K.; Jha, B. Bacterial exopolysaccharides-A perception. J. Basic Microb. 2007, 47, 103-117. [CrossRef] [PubMed]

9. Lim, D.J.; Kim, J.D.; Kim, M.Y.; Yoo, S.H.; Kong, J.Y. Physicochemical properties of the exopolysaccharides produced by marine bacterium Zoogloea sp. KCCM10036. J. Microbiol. Biotechnol. 2007, 17, 979-984. [PubMed]

10. Arun, J.; Selvakumar, S.; Sathishkumar, R.; Moovendhan, M.; Ananthan, G.; Maruthiah, T.; Palavesam, A. In vitro antioxidant activities of an exopolysaccharide from a salt pan bacterium Halolactibacillus miurensis. Carbohydr. Polym. 2017, 155, 400-406. [CrossRef] [PubMed]

11. Heymann, D.; Ruiz-Velasco, C.; Chesneau, J.; Ratiskol, J.; Sinquin, C.; Colliec-Jouault, S. Anti-metastatic properties of a marine bacterial exopolysaccharide-based derivative designed to mimic glycosaminoglycans. Molecules 2016, 21, 309. [CrossRef] [PubMed]

12. Cambon-Bonavita, M.A.; Raguenes, G.; Jean, J.; Vincent, P.; Guezennec, J. A novel polymer produced by a bacterium isolated from a deep-sea hydrothermal vent polychaete annelid. J. Appl. Microbiol. 2002, 93, 310-315. [CrossRef] [PubMed]

13. Le Costaouec, T.; Cerantola, S.; Ropartz, D.; Ratiskol, J.; Sinquin, C.; Colliec-Jouault, S.; Boisset, C. Structural data on a bacterial exopolysaccharide produced by a deep-sea Alteromonas macleodii strain. Carbohydr. Polym. 2012, 90, 49-59. [CrossRef] [PubMed] 
14. Guibaud, G.; Comte, S.; Bordas, F.; Dupuy, S.; Baudu, M. Comparison of the complexation potential of extracellular polymeric substances (EPS), extracted from activated sludges and produced by pure bacteria strains, for cadmium, lead and nickel. Chemosphere 2005, 59, 629-638. [CrossRef] [PubMed]

15. Li, W.; Yu, H. Insight into the roles of microbial extracellular polymer substances in metal biosorption. Bioresour. Technol. 2014, 160, 15-23. [CrossRef] [PubMed]

16. Li, N.; Wei, D.; Wang, S.; Hu, L.; Xu, W.; Du, B.; Wei, Q. Comparative study of the role of extracellular polymeric substances in biosorption of $\mathrm{Ni}(\mathrm{II})$ onto aerobic/anaerobic granular sludge. J. Colloid Interface Sci. 2017, 490, 754-761. [CrossRef] [PubMed]

17. Gopalakannan, V.; Periyasamy, S.; Viswanathan, N. Synthesis of assorted metal ions anchored alginate bentonite biocomposites for Cr(VI) sorption. Carbohydr. Polym. 2016, 151, 1100-1109. [CrossRef] [PubMed]

18. Vijayalakshmi, K.; Gomathi, T.; Latha, S.; Hajeeth, T.; Sudha, P.N. Removal of copper(II) from aqueous solution using nanochitosan/sodium alginate/microcrystalline cellulose beads. Int. J. Biol. Macromol. 2016, 82, 440-452. [CrossRef] [PubMed]

19. Bayramoglu, G.; Yakup Arica, M. Construction a hybrid biosorbent using Scenedesmus quadricauda and Ca-alginate for biosorption of $\mathrm{Cu}(\mathrm{II}), \mathrm{Zn}(\mathrm{II})$ and $\mathrm{Ni}(\mathrm{II})$ : Kinetics and equilibrium studies. Bioresour. Technol. 2009, 100, 186-193. [CrossRef] [PubMed]

20. Vijayaraghavan, K.; Yun, Y.S. Bacterial biosorbents and biosorption. Biotechnol. Adv. 2008, 26, $266-291$. [CrossRef] [PubMed]

21. Salehizadeh, H.; Shojaosadati, S.A. Removal of metal ions from aqueous solution by polysaccharide produced from Bacillus firmus. Water Res. 2003, 37, 4231-4235. [CrossRef]

22. Ye, S.; Zhang, M.; Yang, H.; Wang, H.; Xiao, S.; Liu, Y.; Wang, J. Biosorption of $\mathrm{Cu}^{2+}, \mathrm{Pb}^{2+}$ and $\mathrm{Cr}^{6+}$ by a novel exopolysaccharide from Arthrobacter ps-5. Carbohydr. Polym. 2014, 101, 50-56.

23. Ozturk, S.; Aslim, B.; Suludere, Z.; Tan, S. Metal removal of cyanobacterial exopolysaccharides by uronic acid content and monosaccharide composition. Carbohydr. Polym. 2014, 101, 265-271. [CrossRef] [PubMed]

24. Freire-Nordi, C.S.; Vieira, A.A.H.; Nascimento, O.R. The metal binding capacity of Anabaena spiroides extracellular polysaccharide: An EPR study. Process. Biochem. 2005, 40, 2215-2224. [CrossRef]

25. Kiran, B.; Kaushik, A. Chromium binding capacity of Lyngbya putealis exopolysaccharides. Biochem. Eng. J. 2008, 38, 47-54. [CrossRef]

26. Satpute, S.K.; Banat, I.M.; Dhakephalkar, P.K.; Banpurkar, A.G.; Chopade, B.A. Biosurfactants, bioemulsifiers and exopolysaccharides from marine microorganisms. Biotechnol. Adv. 2010, 28, 436-450. [CrossRef] [PubMed]

27. Pedlera, B.E.; Aluwihareb, L.I.; Azam, F. Single bacterial strain capable of significant contribution to carbon cycling in the surface ocean. Proc. Natl. Acad. Sci. USA 2014, 111, 7202-7207. [CrossRef] [PubMed]

28. Dubreucq, G.; Domon, B.; Fournet, B. Structure determination of a novel uronic acid residue isolated from the exopolysaccharide produced by a bacterium originating from deep sea hydrothermal vents. Carbohydr. Res. 1996, 290, 175-181. [CrossRef]

29. Raguenes, G.; Pignet, P.; Gauthier, G.; Peres, A.; Christen, R.; Rougeaux, H.; Barbier, G.; Guezennec, J. Description of a new polymer-secreting bacterium from a deep-sea hydrothermal vent, Alteromonas macleodii subsp. fijiensis, and preliminary characterization of the polymer. Aquat. Microb. Ecol. 1996, 62, 67-73.

30. Rougeaux, H.; Guezennec, J.; Carlson, R.W.; Kervarec, N.; Pichon, R.; Talaga, P. Structural determination of the exopolysaccharide of Pseudoalteromonas strain HYD 721 isolated from a deep-sea hydrothermal vent. Carbohydr. Res. 1999, 315, 273-285. [CrossRef]

31. Raguenes, G.; Cambon-Bonavita, M.A.; Lohier, J.F.; Boisset, C.; Guezennec, J. A novel, highly viscous polysaccharide excreted by an Alteromonas isolated from a deep-sea hydrothermal vent shrimp. Curr. Microbiol. 2003, 46, 448-452. [CrossRef] [PubMed]

32. Zhang, Z.; Chen, Y.; Wang, R.; Cai, R.; Fu, Y.; Jiao, N. The Fate of marine bacterial exopolysaccharide in natural marine microbial communities. PLOS ONE 2015, 10, e0142690. [CrossRef] [PubMed]

33. Roger, O.; Kervarec, N.; Ratiskol, J.; Colliec-Jouault, S.; Chevolot, L. Structural studies of the main exopolysaccharide produced by the deep-sea bacterium Alteromonas infernus. Carbohydr. Res. 2004, 339, 2371-2380. [CrossRef] [PubMed]

34. Rougeaux, H.; Talaga, P.; Carlson, R.W.; Guezennec, J. Structural studies of an exopolysaccharide produced by Alteromonas macleodii subsp. fijiensis originating from a deep-sea hydrothermal vent. Carbohydr. Res. 1998, 312, 53-59. [PubMed] 
35. Delbarre-Ladrat, C.; Sinquin, C.; Lebellenger, L.; Zykwinska, A.; Colliec-Jouault, S. Exopolysaccharides produced by marine bacteria and their applications as glycosaminoglycan-like molecules. Front. Chem. 2014, 2, 85. [CrossRef] [PubMed]

36. Mata, J.A.; Bejar, V.; Bressollier, P.; Tallon, R.; Urdaci, M.C.; Quesada, E.; Llamas, I. Characterization of exopolysaccharides produced by three moderately halophilic bacteria belonging to the family Alteromonadaceae. J. Appl. Microbiol. 2008, 105, 521-528. [CrossRef] [PubMed]

37. Yoon, J.H.; Kim, I.G.; Kang, K.H.; Oh, T.K.; Park, Y.H. Alteromonas marina sp. nov., isolated from sea water of the East Sea in Korea. Int. J. Syst. Evol. Microbiol. 2003, 53 Pt 5, 1625-1630. [CrossRef] [PubMed]

38. Zhou, W.; Wang, J.; Shen, B.; Hou, W.; Zhang, Y. Biosorption of copper(II) and cadmium(II) by a novel exopolysaccharide secreted from deep-sea mesophilic bacterium. Colloids Surf. B 2009, 72, 295-302. [CrossRef] [PubMed]

39. Cruz, C.C.V.; da Costa, A.C.A.; Henriques, C.A.; Luna, A.S. Kinetic modeling and equilibrium studies during cadmium biosorption by dead Sargassum sp. biomass. Bioresour. Technol. 2004, 91, 249-257. [CrossRef]

40. Wang, F.; $\mathrm{Lu}, \mathrm{X}$; $\mathrm{Li}$, X.Y. Selective removals of heavy metals $\left(\mathrm{Pb}^{2+}, \mathrm{Cu}^{2+}\right.$, and $\left.\mathrm{Cd}^{2+}\right)$ from wastewater by gelation with alginate for effective metal recovery. J. Hazard. Mater. 2016, 308, 75-83. [CrossRef] [PubMed]

41. Loaec, M.; Olier, R.; Guezennec, J. Chelating properties of bacterial exopolysaccharides from deep-sea hydrothermal vents. Carbohydr. Polym. 1998, 35, 65-70. [CrossRef]

42. Kidambi, S.P.; Sundin, G.W.; Palmer, D.A.; Chakrabarty, A.M.; Bender, C.L. Copper as a signal for alginate synthesis in Pseudomonas syringae pv. syringae. Appl. Environ. Microbiol. 1995, 61, 2172-2179. [PubMed]

43. Harvey, R.W.; Luoma, S.N. Effect of adherent bacteria and bacterial extracellular polymers upon assimilation by Macoma baltica of sediment-bound Cd, Zn and Ag. Mar. Ecol. Prog. Ser. 1985, 22, 281-289. [CrossRef]

44. Decho, A.W. Microbial exopolymer secretions in ocean environments: Their role(s) in food webs and marine processes. In Oceanography and Marine Biology: An Annual Review; Barnes, M., Ed.; Aberdeen University Press: Aberdeen, UK, 1990; pp. 73-153.

45. Staub, A.M. Removal of proteins: Sevag method. Methods Carbohydr. Chem. 1965, 5, 5-6.

(C) 2017 by the authors. Licensee MDPI, Basel, Switzerland. This article is an open access article distributed under the terms and conditions of the Creative Commons Attribution (CC BY) license (http:/ / creativecommons.org/licenses/by/4.0/). 